\title{
KNOWLEDGE OF TYPE 2 DIABETES MELLITUS AND ITS RISK FACTORS AMONG ADULT POPULATION IN RURAL AREAS OF WEST DISTRICT OF TRIPURA- A CROSS SECTIONAL STUDY
}

\author{
Saru Kr. Debbarma1, Shyamal Roy², Taranga Reang ${ }^{3}$
}

${ }_{1}^{1}$ Assistant Professor, Department of Medicine, Agartala Government Medical College and GB Pant Hospital, Agartala, Tripura, India. ${ }_{2}^{2}$ Associate Professor, Department of Medicine, Agartala Government Medical College and GB Pant Hospital, Agartala, Tripura, India. ${ }^{3}$ Assistant Professor, Department of Community Medicine, Agartala Government Medical College and GB Pant Hospital, Agartala, Tripura, India.

\begin{tabular}{l} 
ABSTRACT \\
\hline BACKGROUND \\
The incidence of diabetes mellitus is increasing globally, with resulting increase in burden of the same on developing countries. \\
The objectives of this study were- 1 . to assess the knowledge about type 2 diabetes mellitus and its risk factors among adult \\
population and 2. To assess the association of socio demographic profiles with knowledge of diabetes.
\end{tabular}

\section{MATERIALS AND METHODS}

A cross sectional study was conducted among 260 individuals who were selected using multistage random technique.

\section{RESULTS}

The mean age of the study population was 39.4 yrs. Majority of the participants had heard of diabetes. Abstinence from alcohol, smoking, diet modification and regular physical activities could prevent diabetes. Consuming more sweets, high blood pressure, physical inactivity and family history of diabetes were the risk factors for diabetes. It was found that education, family history and self-reported diabetes were significantly associated with knowledge of diabetes.

\section{CONCLUSION}

In spite of having good awareness regarding diabetes mellitus in general, the knowledge level on risk factors was not satisfactory and needs further improvement. Therefore, a special drive has to be given for imparting knowledge to the community people regarding risk factors as this could prevent further occurrence or progress of diabetes.

\section{KEY WORDS}

Diabetes Mellitus Type 2, Knowledge, Adult Population, Complications of Type 2 Diabetes Mellitus.

HOW TO CITE THIS ARTICLE: Debbarma SK, Roy S, Reang T. Knowledge of type 2 diabetes mellitus and its risk factors among adult population in rural areas of west district of Tripura- a cross sectional study. J. Evolution Med. Dent. Sci. 2019;8(02):99-103, DOI: $10.14260 /$ jemds/2019/22

\section{BACKGROUND}

Diabetes Mellitus type $2\left(\mathrm{DM}_{2}\right)$ is more common in the developing countries which are already overburdened by communicable diseases. ${ }^{1}$ The incidence of diabetes mellitus (DM) have continued to increase globally, with the resulting burden resting more heavily on tropical, developing countries.2,3 Type 2 Diabetes Mellitus, the more common type, is being seen in relatively young persons, due to the high burden of environmental and genetic risk factors. ${ }^{3}$ People living with type 2 DM are more vulnerable to different types of both short and long-term complications, which often lead to their premature death. It is predicted that prevalence of $\mathrm{DM}_{2}$ in adults will increase in the next two decades and much of the increase will occur in developing countries where the majority of patients are aged between 45 and 64.4-5 It is estimated that over $70 \%$ of people with diabetes will reside in developing countries by the year 2030.5,6

'Financial or Other Competing Interest': None.

Submission 23-11-2018, Peer Review 27-12-2018,

Acceptance 04-01-2019, Published 14-01-2019.

Corresponding Author:

Dr. Shyamal Roy,

Associate Professor

Department of Medicine,

Agartala Government Medical College and

GB Pant Hospital, Agartala, Tripura, India.

E-mail: tarangareang@gmail.com

DOI: $10.14260 /$ jemds/2019/22
In 2011 the Diabetes Atlas of the International Diabetes Federation (IDF) estimated the global $\mathrm{DM}_{2}$ prevalence in the age group 20-79 years at 8.3\%, which translates into 366.2 million people suffering from $\mathrm{DM}_{2}$ in 2011. The number of people living with $\mathrm{DM}_{2}$ is projected to reach 551.9 million by 2030 (Whiting et al. 2011). ${ }^{7}$ Hyperglycaemia often presents with few symptoms; strict control of blood glucose is needed to prevent many complications of type 2 diabetes mellitus. A blood glucose control goal requires active patient participation in order to master a complex array of selfmanagement skills. These include modifying dietary preferences, implementing exercise regimes, monitoring blood glucose, and adhering to complex medication regimens. ${ }^{8,9}$ Suboptimal treatment can lead to increased use of health care services, reduction in patient's quality of life, and increased health care costs.10,11,12 Inadequate anti diabetes treatment could cause treatment failure, leading to diabetes-related complications, such as retinopathy, neuropathy, nephropathy, etc., which leads to reduced the quality of life. Adequate management required including life style changes and adequate diabetes knowledge of which is considered a key component of diabetes management. Differences in knowledge level had been described based on level of education, gender and social classes. ${ }^{13}$

\section{Objectives}

1. To assess the knowledge of type 2 diabetes mellitus and its risk factors among adult population. 
2. To find the association of sociodemographic profiles with knowledge of diabetes.

\section{MATERIALS AND METHODS}

A cross sectional study was carried out in rural population of West Tripura viz. Lembucherra under Bamutia block and Uttar Devendra Chandra Nagar of Lefunga block under Mohanpur sub-division. Sample size (n) 260 was calculated using formula (n) $=\mathrm{Z1}-\alpha / 2^{2} \mathrm{p}(1-\mathrm{p}) / \mathrm{d}^{2}$, where ' $\mathrm{p}$ ' is $60^{14}$ with precision (d) 6 at 95\% confidence interval and 5\% level of significance including $10 \%$ non response. One eligible member ( $\geq 18$ years) from selected families were included in the study. Any person found suffering from acute or chronic illness was excluded from the study. Multistage random sampling technique was applied for selection of study subjects. Interview schedule was used for individual data collection and data were collected during March to April 2018.

Ethical Clearance was Obtained from Institutional Ethics committee of Agartala Govt. Medical College.

\section{Data Collection}

There are 3 sub divisions in West Tripura district out of which Mohanpur sub-division was randomly selected. Consequently, Uttar Devendra Chandra Nagar and Lembuchera Panchayat under Lefunga and Bhamutia blocks respectively were randomly selected. The population of Uttar Devendra Chandra Nagar and Lembuchera village are approx. 2,520 and 2,903 person's respectively. 15 The list of families were collected from register of the selected village panchayats. In each family with persons of $\geq 18$ years of age were identified and list has been prepared. The simple random sampling technique (Lottery method) was applied for selection of the individual study subjects. If the previously enrolled subjects selected for the consecutive times were not eligible for inclusion in the study. The researcher moved house to house according to the list of identified subjects from the register. The selected subjects who did not refuse were interviewed and one eligible member was selected from each family. Data were collected using a structured and pretested interview schedule which includes details on demography and questions about knowledge of different aspects of diabetes. The questionnaire was prepared in English and translated into local language while conducting interview. Each item had definitive 'yes/no' and other related response key. A scoring system was developed, whereby the total number of correct responses for the knowledge section was calculated for each respondent, and percentage was created. Each correct answer was given one mark and the total mark calculated out of 100 . Knowledge was graded as very good (score $>80 \%$ ), good (60-80\%), average (40-60\%) and poor $(<40 \%)$. Each questionnaire took approximately 15 minutes to administer. The participants were requested to participate in the study voluntarily. Informed consent was obtained from the participants before conducting the study. The information so collected was kept confidential and anonymous. The ethical clearance was obtained from Institutional Ethics Committee (IEC) of Agartala Govt Medical College.

\section{Data Analysis}

Data were entered in the computer in a prepared master chart and coded. After shorting and coding the data were analyzed. Data were analyzed using the Microsoft excel 2007. Descriptive statistics such as mean, standard deviation and frequencies were analyzed. For inferential statistics like Chisquare $\left(\mathrm{X}^{2}\right)$ test was used to determine the strength of association between dependent and independent variables. $P$ values $<0.05$ were considered as statistically significant.

\section{RESULTS}

The study areas are rural plain area under West district of Tripura. Both ethnic and non-ethnic groups of population are living in the area. Majority of the family are dependent on cultivation. Over all 260 participants included in the study and data so collected were analyzed. During data collection 11 houses were found locked and no person over 18 years of age was available in 8 houses. The researcher reached 279 houses to achieve 260 samples in the study. The mean age (SD) of the study population was $39.43( \pm 15.336)$ yrs. The mean age for male and female were 41.24 ( \pm 16.043) and 37.99 ( \pm 14.648 ) years respectively. The study showed that in most of the houses the respondents age group were 18-30 years. Majority were female (55.8\%) and from Lembuchera village $(73.5 \%)$ under Bhamutia block of West district of Tripura. (Table 1) Nearly sixty (58.8\%) percent were from nuclear family and remaining $41.2 \%$ joint family. More than eleven percent $(11.5 \%)$ of the participants has self-reported diabetes whereas $88.5 \%$ had not. More than twenty-one (21.2\%) percent has family history of diabetes among the study participants. Majority (80.0) of the participants heard of diabetes, it is due to excess sugar in blood (67.3\%) and more numbers of peoples are affected (44.2\%). If parents are diabetic their offspring may suffer from diabetes (34.6\%). More than half $(53.7 \%)$ said that diabetes can be prevented. Abstinence from alcohol (50.8\%), smoking (50.0\%), diet modification (59.1\%) and regular physical works can prevent diabetes. Nearly thirty-four $(33.7 \%)$ percent mentioned that they knew about complications of diabetes and nearly thirty eight percent $(37.5 \%)$ said that foot care is needed for diabetes patients to prevent complications. It was found that nearly twenty percent $(19.9 \%)$ said that consumption of more sweets followed by overweight (8.2\%), high blood pressure, sweets and lack of physical activity (3.9\%), high blood pressure $(2.7 \%)$, family history of diabetes $(1.6 \%)$, lack of physical activities $(10.8 \%)$ are the risk factors for diabetes. Majority (51.5\%) did not know which organs are affected due to diabetes. Whereas $13.5 \%$ each for kidneys and eyes followed by eyes, kidneys and lungs together $(13.1 \%)$ and heart $(0.8 \%)$ are affected. Majority (62.3\%) said that healthy diet and physical exercise can help prevent diabetes. Nearly fifty percent $(48.5 \%)$ were having very good, $21.5 \%$ good, $27.7 \%$ average and only $8.1 \%$ had poor knowledge of diabetes. It was found that education, family history and selfreported diabetes were significantly associated with knowledge of diabetes $(\mathrm{p}<0.05)$. (Table 2$)$. 


\begin{tabular}{|c|c|c|c|}
\hline \multicolumn{2}{|c|}{ Variables } & $\begin{array}{c}\text { Number } \\
(\mathrm{N})\end{array}$ & \begin{tabular}{|c|} 
Percentage \\
$(\%)$
\end{tabular} \\
\hline \multirow{5}{*}{$\begin{array}{c}\text { Age group } \\
\text { (yrs) }\end{array}$} & $18-30$ yrs. & 98 & 37.7 \\
\hline & $30-40$ yrs. & 62 & 23.8 \\
\hline & $40-50$ yrs. & 39 & 15.0 \\
\hline & $50-60$ yrs. & 33 & 12.7 \\
\hline & $>60 y r s$ & 28 & 10.8 \\
\hline \multirow{2}{*}{ Sex } & Male & 115 & 44.2 \\
\hline & Female & 145 & 55.8 \\
\hline \multirow[t]{2}{*}{ Address } & $\begin{array}{l}\text { Uttar Devendra } \\
\text { Chandra Nagar }\end{array}$ & 69 & 26.5 \\
\hline & Lembuchera & 191 & 73.5 \\
\hline \multirow{4}{*}{ Literacy } & Illiterate & 45 & 17.3 \\
\hline & $\begin{array}{c}\text { Primary/upper } \\
\text { primary }\end{array}$ & 144 & 55.4 \\
\hline & HS \& HS+2 & 53 & 20.4 \\
\hline & $\begin{array}{c}\text { Graduate and } \\
\text { above }\end{array}$ & 18 & 6.9 \\
\hline \multirow{6}{*}{ Occupation } & Unemployed & 34 & 13.1 \\
\hline & Retired & 10 & 3.8 \\
\hline & Unskilled & 73 & 28.1 \\
\hline & Homemaker & 110 & 42.3 \\
\hline & Students & 10 & 3.8 \\
\hline & $\begin{array}{c}\text { Professional and } \\
\text { skilled }\end{array}$ & 23 & 8.8 \\
\hline \multirow{5}{*}{$\begin{array}{c}\text { Income } \\
\text { (Rs.)/Month }\end{array}$} & $\leq 5000 /-$ & 123 & 47.3 \\
\hline & $5000-10000 /-$ & 84 & 32.3 \\
\hline & 10000-15000/- & 15 & 5.8 \\
\hline & $15000-20000 /-$ & 13 & 5.0 \\
\hline & $>20000 /-$ & 25 & 9.6 \\
\hline \multirow{2}{*}{ Religion } & Hindu & 259 & 99.6 \\
\hline & Christian & 1 & 0.4 \\
\hline
\end{tabular}

\begin{tabular}{|c|c|c|c|c|c|}
\hline \multirow[b]{2}{*}{ Variables } & \multicolumn{4}{|c|}{ Knowledge Score } & \multirow[b]{2}{*}{$\begin{array}{c}\text { p- } \\
\text { value }\end{array}$} \\
\hline & $\begin{array}{l}<40 \%, \\
\text { N (\%) }\end{array}$ & \begin{tabular}{|c|}
$40-60 \%$, \\
N (\%)
\end{tabular} & \begin{tabular}{|c} 
60-80\%, \\
N (\%)
\end{tabular} & $\begin{array}{l}>80 \%, \\
\text { N (\%) }\end{array}$ & \\
\hline \multicolumn{6}{|c|}{ Age Group (Yrs.) } \\
\hline $18-30$ yrs. & $7(7.1)$ & $17(17.3)$ & $20(20.4)$ & $54(55.1)$ & \multirow{5}{*}{0.112} \\
\hline $30-40$ yrs. & $5(8.1)$ & $19(30.6)$ & $12(19.4)$ & $26(41.9)$ & \\
\hline $40-50$ yrs. & $4(8.1)$ & $12(30.6)$ & $5(19.4)$ & $18(41.9)$ & \\
\hline $50-60$ yrs. & $1(3.0$ & $13(39.4)$ & $4(12.1)$ & $15(45.5)$ & \\
\hline$>60$ yrs. & $4(14.3)$ & $11(39.3)$ & $0(0.0)$ & $13(46.4)$ & \\
\hline \multicolumn{6}{|c|}{ Sex } \\
\hline Male & $9(7.8)$ & $38(33.0)$ & & $52(45.2)$ & \multirow{2}{*}{0.384} \\
\hline Feale & $12(8.3)$ & $34(23.4)$ & 250 & 74 & \\
\hline \multicolumn{6}{|c|}{ Address } \\
\hline Uttar DC & $5(7.2)$ & $20(29.0)$ & 11 & $33(47.8)$ & \multirow{2}{*}{0.986} \\
\hline Lembuc & $16(8.4)$ & $52(27.2)$ & 301 & & \\
\hline \multicolumn{6}{|c|}{ Literacy } \\
\hline \begin{tabular}{|l|} 
Illiterate \\
\end{tabular} & $9(6.2)$ & 37 (25.7) & $24(16.7)$ & $74(51.4)$ & \multirow{4}{*}{0.012} \\
\hline $\begin{array}{c}\text { Primary/upper } \\
\text { primary }\end{array}$ & $\begin{array}{c}7 \\
(33.3 \%)\end{array}$ & $\begin{array}{c}20 \\
(27.8 \%)\end{array}$ & $\begin{array}{c}11 \\
(26.8 \%)\end{array}$ & $\begin{array}{c}15 \\
(11.9 \%)\end{array}$ & \\
\hline HS \& HS (+2) & $3(16.7)$ & $7(38.9)$ & $2(11.1)$ & $6(33.3)$ & \\
\hline $\begin{array}{c}\text { Graduate and } \\
\text { Above }\end{array}$ & $9(7.3)$ & 37 (25.7) & 24 (16.7) & $74(51.4)$ & \\
\hline \multicolumn{6}{|c|}{ Occupation } \\
\hline Unemployed & $3(8.8)$ & $9(26.5)$ & $4(11.8)$ & $18(53.0)$ & \multirow{6}{*}{0.559} \\
\hline Retired & $1(10.0)$ & $3(30.0)$ & $1(10.0)$ & $5(50.0)$ & \\
\hline Unskilled & $6(8.2)$ & $19(26.0)$ & $12(16.4)$ & $36(49.3)$ & \\
\hline Homemaker & $9(8.2)$ & $25(22.7)$ & $20(18.2)$ & $56(51.0)$ & \\
\hline Students & $0(0.0)$ & $4(40.0)$ & $3(30.0)$ & $3(30.0)$ & \\
\hline $\begin{array}{l}\text { Professional } \\
\text { and skilled }\end{array}$ & $2(8.7)$ & 12 (52.2) & $1(4.3)$ & $8(34.8)$ & \\
\hline
\end{tabular}

\begin{tabular}{|c|c|c|c|c|c|}
\hline \multicolumn{7}{|c|}{ Self-Reported Diabetes } \\
\hline Yes & $1(3.3)$ & $17(56.7)$ & $3(10.0)$ & $9(30.0)$ & \multirow{2}{*}{0.002} \\
\cline { 1 - 4 } No & $\begin{array}{c}20 \\
(8.7)\end{array}$ & $\begin{array}{c}55 \\
(24.0)\end{array}$ & $\begin{array}{c}38 \\
(16.5)\end{array}$ & $\begin{array}{c}117 \\
(50.8)\end{array}$ & \\
\hline \multicolumn{6}{|c|}{ Family History } \\
\hline Yes & $9(16.4)$ & $27(49.1)$ & $9(16.4)$ & $10(18.2)$ & \multirow{2}{*}{0.000} \\
\hline \multirow{2}{*}{ No } & 12 & 45 & 32 & 116 & 0 \\
& $(5.9)$ & $(22.0)$ & $(15.6)$ & $(56.6)$ & \\
\hline Table 2. The Association of Sociodemographic Variables \\
with Knowledge Score \\
\hline
\end{tabular}

\section{DISCUSSION}

The present study was conducted among rural population of west district of Tripura and knowledge and risk factors of diabetes were analyzed. More than fifty percent were represented by females with mean age (SD) of 39.43 $( \pm 15.336$ ) years. Majority of the participants were literate and studied up to primary/upper primary level of education. Korian B et al (2016) reported that the mean age (SD) of the respondents was $47.74( \pm 15.74)$ years and predominantly females (74.6\%). More than fifty percent (55.7\%) among study population had high school and higher secondary education. ${ }^{16}$ Choudhary VS et al (2015) reported that mean age was $41( \pm 15)$ years. ${ }^{17}$ Muninarayana $C$ et al reported that the age group was $30-45$ years and $54 \%$ were females. About $56.3 \%$ of them were literates and $80 \%$ was sedentary in occupation. ${ }^{18}$ Imtiaz KS et al (2016) reported that majority $(47.50 \%)$ were in the age group of $21-30$ years and $80.5 \%$ were literate. ${ }^{19}$ It was almost comparable with present study. In present study kidney and eye problem were most common complications stated by the participants. Majority of the participants heard of diabetes, it was due to increase sugar in blood and more numbers of peoples were affected. More than fifty percent said that diabetes could be prevented. Abstinence from alcohol, smoking, diet modification and regular physical activities can prevent diabetes. Nearly thirty four percent mentioned that they knew about complications of diabetes and nearly thirty eight percent said that foot care was needed to prevent complications. Kurian B (2016) ${ }^{16}$ and Deepa $M$ et al (2005) ${ }^{20}$ reported that almost similar results. Muninarayana $\mathrm{C}$ et al reported that $50.8 \%$ of the respondents were aware of the disease and $45 \%$ of respondents were aware of the risk factors diabetes mellitus. The most common complications reported by the non-diabetic participants were eye problems $(7.1 \%)$ followed by kidney disease (6.4\%), foot problems $(6.1 \%)$ and heart attacks (5.7\%). Even among diabetes subjects only $74.2 \%$ were aware that diabetes could produce some complications. ${ }^{18}$ Choudhary VS et al (2015) reported that $46.66 \%$ adults had any awareness of type 2 diabetes mellitus. Awareness of risk factor was present in $25.33 \%$ while awareness about complication associated with the type 2 diabetes mellitus was $28.33 \% .{ }^{17}$ Imtiaz KS et al (2016) reported that majority of respondents heard about type 2 diabetes mellitus. ${ }^{19}$ Knowledge is a logical prerequisite for the intentional performance of health related behaviour. As knowledge accumulates, changes in attitudes are initiated and over a period time it results in behaviour change. ${ }^{21}$ Knowledge of diabetes is of paramount importance in determining intended behaviour such as lifestyle modifications and adherence to treatment. 16 It is well established in medical literature that prevention of diabetes cannot be obtained unless general population including high risk groups know how to protect themselves.22-24 It is well 
understood that risk factor knowledge is prerequisite for prevention of disease, and inability to recognize risk factors impedes preventive efforts such as adoption of healthy lifestyle. ${ }^{25}$ As diabetes prevention is primarily dependent on altering lifestyle and increasing levels of physical activity improving knowledge about the risk factors of diabetes must receive urgent attention. ${ }^{26}$ Kurian $B$ et al reported that except for diet which was stated by over half of the respondents (57.1\%), other important risk factors such as physical inactivity, obesity, smoking, alcohol was cited by $<5 \%$ of respondents. Only $17.2 \%$ of respondents mentioned hereditary as a risk factor for diabetes. ${ }^{16}$ The awareness on risk factors was higher than that population-based study conducted in Chennai urban rural epidemiology study which demonstrated that $<12 \%$ were aware that obesity and physical inactivity could lead to diabetes. In present study more than sixty three percent did not know which organs are more affected as a complication of diabetes. Kurian B et al reported that awareness on complications of diabetes was poor as nearly half of respondents could not cite any of the complications. Even among diabetics one third were unaware of complications. ${ }^{16}$ The present study results were also almost comparable with the findings of studies done elsewhere.22,23,26,27 It partly reflects that patients were not sensitized about the complications of diabetes which could have dreadful consequences in terms of mortality and morbidity. Several reasons have been cited for this including lack of time, an inappropriate way of providing information, lack of trained support staff like diabetic educators. ${ }^{26,}{ }^{28}$ In present study more than fifty percent knew that diabetes could be prevented. Kurian B et al reported that $72.3 \%$ of study population knew that diabetes could be prevented. ${ }^{16}$ Few studies, have documented the role of preventive measures in control of diabetes. ${ }^{29,} 30$ Having a family member with diabetes mellitus was likely to be more aware than their counterparts. Education also had a similar influence on knowledge. A study conducted among African American adults suggested that family history of diabetes was associated with better awareness of diabetes. ${ }^{31}$ In present study family history of diabetes was associated with better awareness of diabetes which was almost comparable with African studies. 31

\section{CONCLUSION}

Literate persons were more conscious compared to others. In spite of having good awareness regarding diabetes mellitus in general, the knowledge level on risk factors was not satisfactory and needs further improvement. Therefore, a special drive has to be given for imparting knowledge to the community people regarding risk factors as this could prevent further occurrence or progression of diabetes and delay the onset among the population at risk individuals. Moreover, knowledge about organs affected was not satisfactory. Therefore, for achieving successful result, it was necessary to educate persons on importance of life style changes and shift to healthy diet consumption and to recognize early diabetes related complications once it is diagnosed.

\section{Limitations}

The study sample was small and conducted in a localized rural population. Equal representation from different study areas could not be made due to difficult hilly terrain. Hence, this study cannot be generalized.

\section{ACKNOWLEDGEMENT}

We thank the participants without whom this study would not have been possible and completed in time.

\section{REFERENCES}

[1] Ogbera AO, Kuku SF. Insulin use, prescription patterns, regimens and costs-a narrative from a developing country. Diabetology \& Metabolic Syndrome 2012;4(1):50.

[2] Wild S, Roglic G, Green A, et al. Global prevalence of diabetes: estimates for the year 2000 and projections for 2030. Diabetes Care 2004;27(5):1047-53.

[3] Lindagren CM, Hirschhorn JN. The genetics of type II Diabetes. Endocrinologist 2001;11:178-87.

[4] Murray CJL, Lopez AD. Alternative projections of mortality and disability by cause. 1990-2020. Global Burden of Disease Study. Lancet 1997;349(9064):1498-504.

[5] Shaw JE, Sicree RA, Zimmet PZ. Global estimates of the prevalence of diabetes for 2010 and 2030. Diabetes Res Clin Pract 2010;87(1):4-14.

[6] Inzucchi SE. Diabetes Facts and Guidelines. Takeda Pharmaceuticals, 2011. Yale Diabetes Center, Yale University, North America, Inc., https://www.yumpu.com/en/document/view/58090 26/diabetes-facts-and-guidelines-endocrinology-yaleuniversity. (Accessed on 24/5/2017).

[7] Whiting DR, Guariguata L, Weil C, et al. IDF diabetes atlas: global estimates of the prevalence of diabetes for 2011 and 2030. Diabetes Res Clin Pract 2011;94(3):311-21.

[8] Rozenfeld Y, Hunt JS, Plauschinat C, et al. Oral antidiabetic medication adherence and glycemic control in managed care. Am J Manag Care 2008;14(2):71-5.

[9] Ho PM, Rumsfeld JS, Masoudi FA, et al. Effect of medication non-adherence on hospitalization and mortality among patients with diabetes mellitus. Arch Intern Med 2006;166(17):1836-41.

[10] World Health Organization. Adherence to long-term therapies: evidence for action. World Health Organization, Geneva, Switzerland 2003.

[11] Lau DT, Nau DP. Oral antihyperglycemic medication no adherence and subsequent hospitalization among individuals with type 2 diabetes. Diabetes Care 2004;27(9):2149-53.

[12] Sokol MC, McGuigan KA, Verbrugge RR, et al. Impact of medication adherence on hospitalization risk and healthcare cost. Med Care 2005;43(6):521-30.

[13] Al-Sarihin KK, Bani-Khaled RN, Haddad FH, et al. Diabetes knowledge among patients with diabetes mellitus at King Hussein hospital. Journal of The Royal Medical Services 2012;19(1):72-7.

[14] Anjana RM, Deepa M, Pradeepa R, et al. Prevalence of diabetes and pre-diabetes in 15 states of India: results from the ICMR-INDIAB population-based crosssectional study. Lancet Diabetes Endocrinol 
2017;5(8):585-96. http://dx.doi.org/10.1016/S22138587(17)30174-2). www.thelancet.com/diabetesendocrinology.

[15] India 2011. (Accessed on 12/01/2018) http://northeasttourism.gov.in/agartala.html\#sthash. pwlYAUzR.dpbs.

[16] Kurian B, Qurieshi MA, Ganesh R, et al. A communitybased study on knowledge of diabetes mellitus among adults in a rural population of Kerala. Int J NonCommun Dis 2016;1(2):59-64.

[17] Choudhary VS, Chaudhary G. A descriptive study to assess the knowledge regarding diabetes mellitus, its risk factors and complication among the rural community sadiq, faridkot (Punjab). Asian J Nur Edu and Research 2015;5(2):251-3.

[18] Muninarayana C, Balachandra G, Hiremath SG, et al. Prevalence and awareness regarding diabetes mellitus in rural Tamaka, Kolar. Int J Diabetes Dev Ctries 2010;30(1):18-21.

[19] Imtiaz KS, Chowdhury M, Nazneen $\mathrm{MH}$, et al. Knowledge regarding diabetes mellitus among rural people in a selected area of Bangladesh. Northern International Medical College Journal 2016;7:131-4.

[20] Deepa M, Deepa R, Shanthirani CS, et al. Awareness and knowledge of diabetes in Chennai - The Chennai Urban Rural Epidemiology Study [CURES - 9]. JAPI 2005;53:283-7.

[21] Baranowski T, Cullen KW, Nicklas T, et al. Are current healths behavioural change models helpful in guiding prevention of weight gain efforts? Obes Res 2003;(Suppl 11):23S-43S.

[22] McManus RM, Stitt LW, Bargh GJ. Population survey of diabetes knowledge and protective behaviours. Can J Diabetes 2006;30(3):256-63.
[23] Fritsche A, Stumvoll M, Goebbel S, et al. Long term effect of a structured inpatient diabetes teaching and treatment programme in type 2 diabetic patients: influence of mode of follow up. Diabetes Res Clin Pract 1999;46(2):135-41.

[24] Nicolucci A, Ciccarone E, Consoli A, et al. Relationship between patient practices oriented knowledge and metabolic control in intensively treated type 1 diabetic patients: results of the validation of the knowledge and practices diabetes questionnaire. Diabetes Nutr Metab 2000;13(5):276-83.

[25] Janz NK, Becker MH. The health belief model: a decade later. Health Educ Q 1984;11(1):1-47.

[26] Al Shafaee MA, Al Shukaili S, Rizvi SG, et al. Knowledge and perceptions of diabetes in a semi-urban Omani population. BMC Public Health 2008;8:249.

[27] Gulabani M, John M, Isaac R. Knowledge of diabetes, its treatment and complications amongst diabetic patients in a tertiary care hospital. Indian J Community Med 2008;33(3):204-6.

[28] Kapur A. Influence of socio economic factors on diabetes care. Int J Diabetes Dev Ctries 2001;21:77-85.

[29] Knowler WC, Barrett-Connor E, Fowler SE, et al. Reduction in the incidence of type 2 diabetes with lifestyle intervention or metformin. $\mathrm{N}$ Engl J Med 2002;346(6):393-403.

[30] Tuomilehto J, Lindström J, Eriksson JG, et al. Prevention of type 2 diabetes mellitus by changes in lifestyle among subjects with impaired glucose tolerance. N Engl J Med 2001;344(18):1343-50.

[31] Baptiste-Roberts K, Gary TL, Beckles GL, et al. Family history of diabetes, awareness of risk factors and health behaviours among African Americans. Am J Public Health 2007;97(5):907-12. 